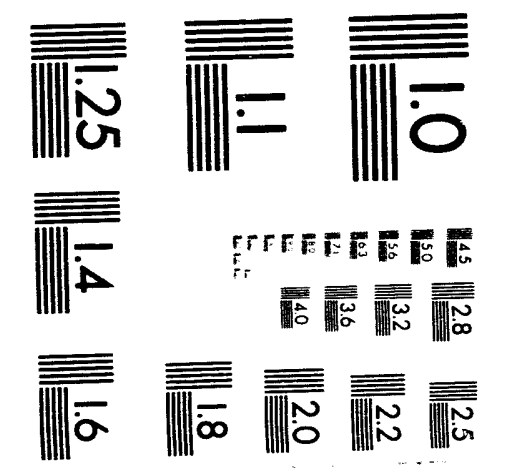



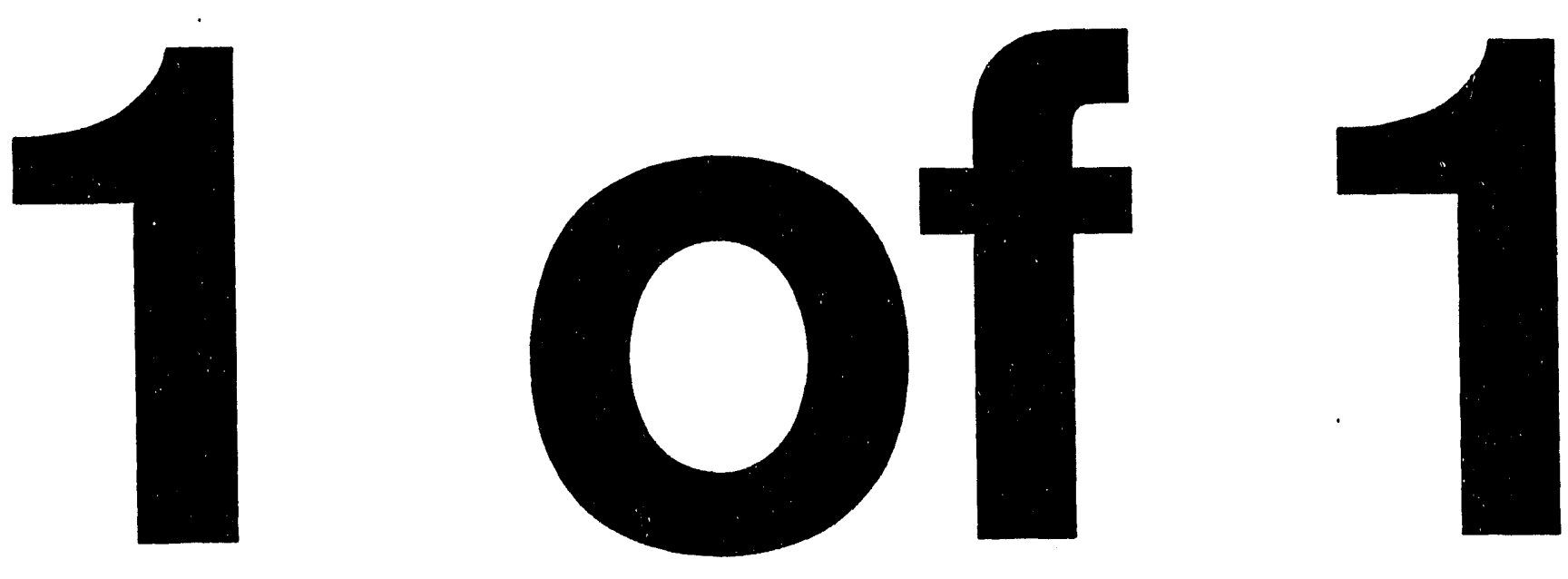


\title{
DEVELOPMENT OF BIOLOGICAL COAL GASIFICATION (MICGAS PROCESS)
}

\section{2th Quarterly Report}

DOE-METC Contract No. DE-AC21-90MC27226

\author{
Submitted to: \\ Department of Energy \\ Morgantown Energy Technology Center \\ P.O. Box 880 \\ 3610 Collins Ferry Road \\ Morgantown, WV 26507-0880
}

July 29, 1993

\author{
Submitted by: \\ ARCTECH, InC. \\ 14100 Park Meadow Dr. \\ Chantilly, VA 22021
}

\section{DISCLAIMER}

This report was prepared as an account of work sponsored by an agency of the United States Government. Neither the United States Government nor any agency thereof, nor any of their employees, makes any warranty, express or implied, or assumes any legal liability or responsibility for the accuracy, completeness, or usefulness of any information, apparatus, product, or process disclosed, or represents that its use would not infringe privately owned rights. Reference herein to any specific commercial product, process, or service by trade name, trademark, manufacturer, or otherwise does not necessarily constitute or imply its endorsement, recommendation, or favoring by the United States Government or any agency thereof. The views and opinions of authors expressed herein do not necessarily state or reflect those of the United States Government or any agency thereof.

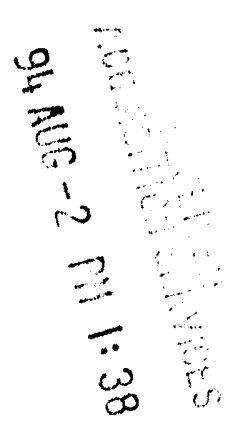

\section{MASTER}

DISThiBution of THIS DBcumevi is umumithe 
1. CONTRACT: For the DOE contract \# DE-AC21-9OMC27226 MOD AOOCC following tasks were completed:

Task 1. NEPA Compliance and Updated Test Plan This task has been completed.

\section{Task 2. Enhance Methane Production}

subtask 2.1 Bacterial strain Improvement. Several experiments were conducted to study the efficiency of granulated sludge consortium (GSC) on the biomethanation of Texas lignite (TXL). With an aim of obtaining a better culture than MiC-1, GSC was used as inoculum at different concentrations $(0 \%, 1 \%$ and $10 \%)$. The experiments were carried out in $60-\mathrm{mL}$ vials containing $40 \mathrm{~mL} 0.1 \%$ SNTM + TXL + GSC.

1. The first experiment was conducted under anaerobic conditions $\left(\mathrm{N}_{2}: \mathrm{CO}_{2}\right)$ in $60-\mathrm{mL}$ vials containing $40 \mathrm{~mL} 0.01 \% \mathrm{SNTM}+1 \% \mathrm{TXL}$ $+10 \%$ GSC. All vials (control and experimental) were incubated under static conditions at $37^{\circ} \mathrm{C}$. Methane production was measured periodically in the vial headspace in all experimental vials. After 20 days of incubation, methane was found to be up to $67 \mathrm{~mole}$. VFA analysis shows insignificant quantities of acetic, propionic, butyric, isobutyric, valeric and isocaproic acids. Caproic acid was at 32-34 ppm concentration which is unusual. As this was the first experiment with the GSC, the occurrence of caproic acid will be further investigated.

2. The second experiment was conducted to determine whether $\mathrm{CH}_{4}$ production was from biogasification of coal or from substrates used for growing the GSC. The GSC was maintained in acetate, butyrate and propionate medium. Some "residual" quantities of these substrates might affect $\mathrm{CH}_{4}$ production. That Is why this experiment was conducted as the previous one, but $1 \%$ or $10 \%$ "washed or unwashed" GSC was used. The GSC was "washed" three times with sterile distilled $\mathrm{H}_{2} \mathrm{O}(40-45 \mathrm{~mL})$. Methane accumulation was negligible $(8 \mathrm{cc})$ in the vials that contained only 1\% GSC ("washed or unwashed") during the cultivation period. There was no significant difference in $\mathrm{CH}_{4}$ production in the vials that contained 10\% "washed or unwashed" GSC. The average $\mathrm{CH}_{4}$ produced for this experiment was $61 \mathrm{CC}$ in each vial.

3. The effect of two different anaerobic conditions $\left(\mathrm{N}_{2}: \mathrm{CO}_{2}\right.$ and $\mathrm{H}_{2}: \mathrm{N}_{2}$ ) on biomethanation of Texas Iignite was also studied. The logic for this experiment was to test whether $\mathrm{H}_{2}$ in $\mathrm{H}_{2}: \mathrm{N}_{2}$ 
mixture can serve as an $\mathrm{H}_{2}$ donor to the $\mathrm{Ch}_{4}$ formation during biogasification of coal at $1 \%$ and $10 \%$ solids loadings. The experiment was conducted in $60-\mathrm{mL}$ vials that contained $0.1 \%$ SNTM $+1 \%$ or $10 \% \mathrm{TXL}+10 \% \mathrm{GSC}$ in two sets. The medium in each set of control and experimental vials was purged with a mixture of deoxygenated $\mathrm{H}_{2}: \mathrm{N}_{2}(60: 40)$ or $\mathrm{N}_{2}: \mathrm{CO}_{2} \quad(80: 20)$.

There was no significant difference in the total biogas production between the control and experimental vials. However, in the " $\mathrm{N}_{2}: \mathrm{CO}_{2}$ " set total gas production was approximately 15\% higher. The cumulative methane production decreased with an increase in the solids loadings from $1 \%$ to $10 \%$. While $\mathrm{CO}_{2}$ concentrations increased in both experimental sets (Figure 1). These results confirm our previous observations on the inhibitory effect of increased solids loadings on biomethanation of TXL. This phenomenon might be due to the excessive liberation of $\mathrm{CO}_{2}$ at higher $\mathrm{T} x \mathrm{~L}$ loadings and will be further investigated.

There were slight differences in the protein and COD concentrations in the experimental vials with $1 \%$ and $10 \% \mathrm{TXL}$. Maximum protein content was observed in the vials that contained $10 \% \mathrm{TXL}$ and head space of $\mathrm{N}_{2}: \mathrm{CO}_{2}$. On the other hand, maximum $C O D$ concentration was not affected by the composition of head space gas mixture. The two anaerobic conditions used $\left(\mathrm{H}_{2}: \mathrm{N}_{2}\right.$ and $\left.\mathrm{N}_{2}: \mathrm{CO}_{2}\right)$ had insignificant influence on $\mathrm{COD}$ (39.6 and $34.1 \mathrm{~g} \mathrm{O} \mathrm{O}_{2} / \mathrm{L}$, respectively). These COD values in the experimental vials were $5-6$ times higher compared to those in control vials.

The concentration of VFAs varied during the course of the experiments (Figures 2-4). In both experimental sets (with 1\% and $10 \% \mathrm{~T} \times \mathrm{L}$ ) less propionate and isobutyrate was observed than in the control vials. Nonetheless, in all cases propionate accumulation was the highest among the VFAs monitored. This result indicates a limiting factor for overall $\mathrm{CH}_{4}$ production from the TxL. Maximum isovalerate concentration (60.75 ppm) was obtained on day 21 in experimental vials that contained 10\% GSC and 10\% TxL under $\mathrm{N}_{2}: \mathrm{CO}_{2}$. Heptanoic acid was observed in the experimental vials after 10-14 days of cultivation. Maximum production of this acid (26.45 ppm) was observed on day 21 in the experimental vials containing $1 \%$ TxL. The appearance of isovaleric acid peak coincided with maximum concentration of heptanoic acid. This phenomenon was not observed in any of the previous experiments with TxL and Mic-1 consortium. The appearance of heptanoic and isocaproic acids seems to be due to the metabolism of GSC on the TxL. Further experiments to confirm the accumulation ofpropionate (Figure 4), and higher production of isovalerate and heptanoate (Figure 3) are planned. 
subtask 2.2 Addition of co-substrate. Inoclilum for the experiment on the addition of co-substrates (such as methanol, citrate, oxalate, succinate, etc.) for enhancement of TxL biomethanation has been prepared. The inoculum was obtained by centrifuging the liquid contents from the vials, that contained $1 \% \mathrm{TxL}$ and $10 \mathrm{mM}$ citrate. The experiment is planned for the next reporting period.

subtask 2.3 Low-cost Nutrient Amendment. For this experiment, several samples of sewage sludge have been taken from a local wastewater treatment plant. The plan is to solubilize the sludge with $\mathrm{NaOH}$ and then use it as a nitrogen supplement to evaluate its effectiveness in comparison with Hoffmann's Dried blood and Sheftone $\mathrm{T}^{\mathrm{TM}}$. Cost analysis will be done in order to evaluate the cost effectiveness of the medium for biogasification of Texas lignite.

\section{Conclusions:}

- Granulated sludge consortium (GSC) could be used for biomethanation of TXL.

- "Washed or unwashed" GSC did not influence $\mathrm{CH}_{4}$ production.

- Anaerobic conditions containing deoxygenated $\mathrm{N}_{2}: \mathrm{CO}_{2}$ anaerobic conditions provide better biomethanation of TXL.

- The appearance of heptanoic and isocaproic acids seems to be due to the metabolism of GSC on TxL.

\section{Planned Future work:}

- Study the effect of $\mathrm{pH}$ of the culture medium on biogasification of TXL.

- Investigate the effect of co-substrates on biomethanation of TxL.

- Confirm the effect of methanol as an additional hydrogen donor for enhancement of biogasification of TXL. 

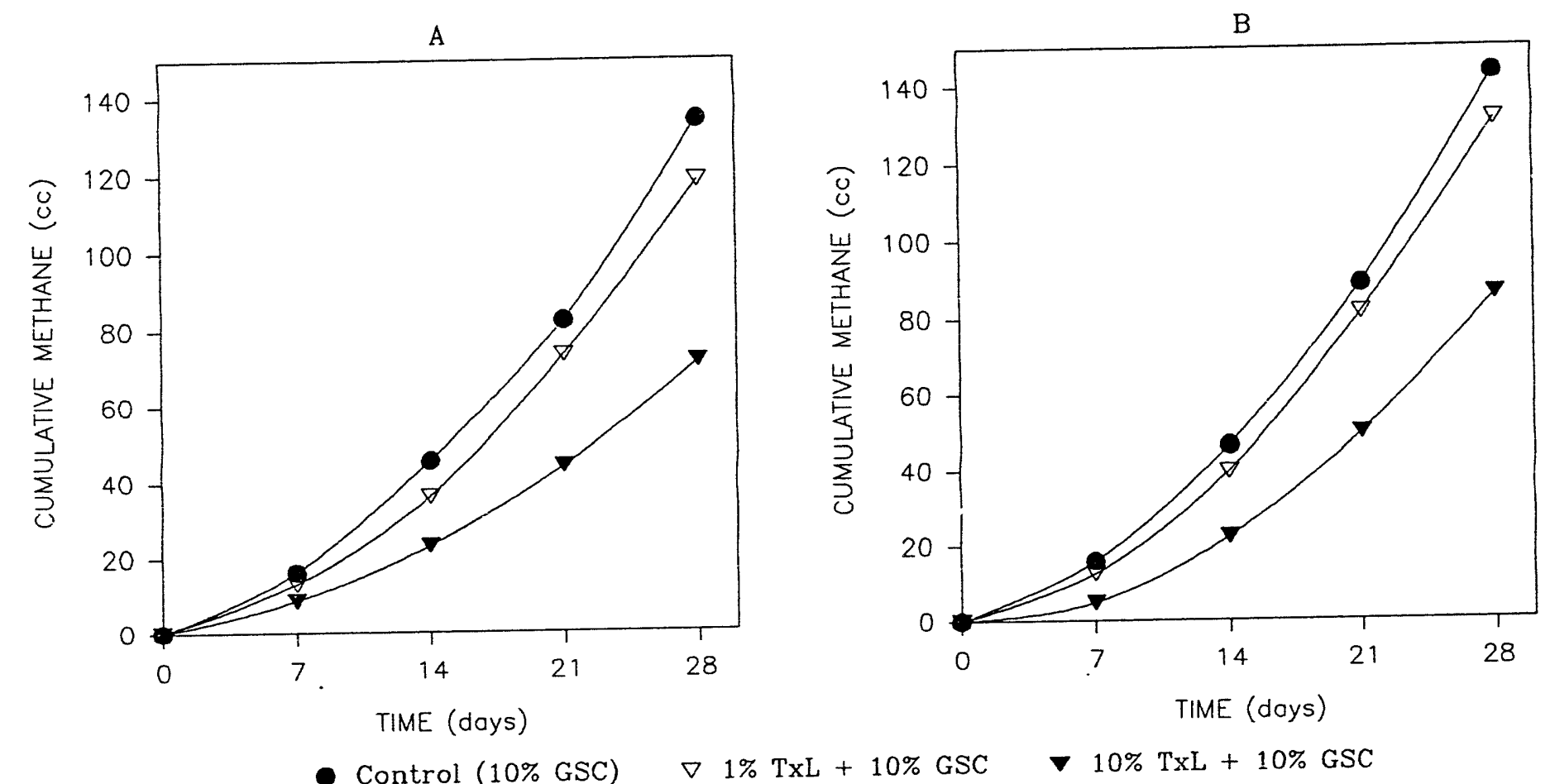

- Control (10\% GSC)

$\nabla 1 \% \mathrm{TxL}+10 \%$ GSC

Figure 1. Influence of Different Anaerobic Conditions $\mathrm{H}_{2}: \mathrm{N}_{2}$ (A) and $\mathrm{N}_{2}: \mathrm{CO}_{2}$ (B) on Cumulative Methane Production by Granulated Sludge Consortium (GSC). 
$1 \% \mathrm{TxL}$
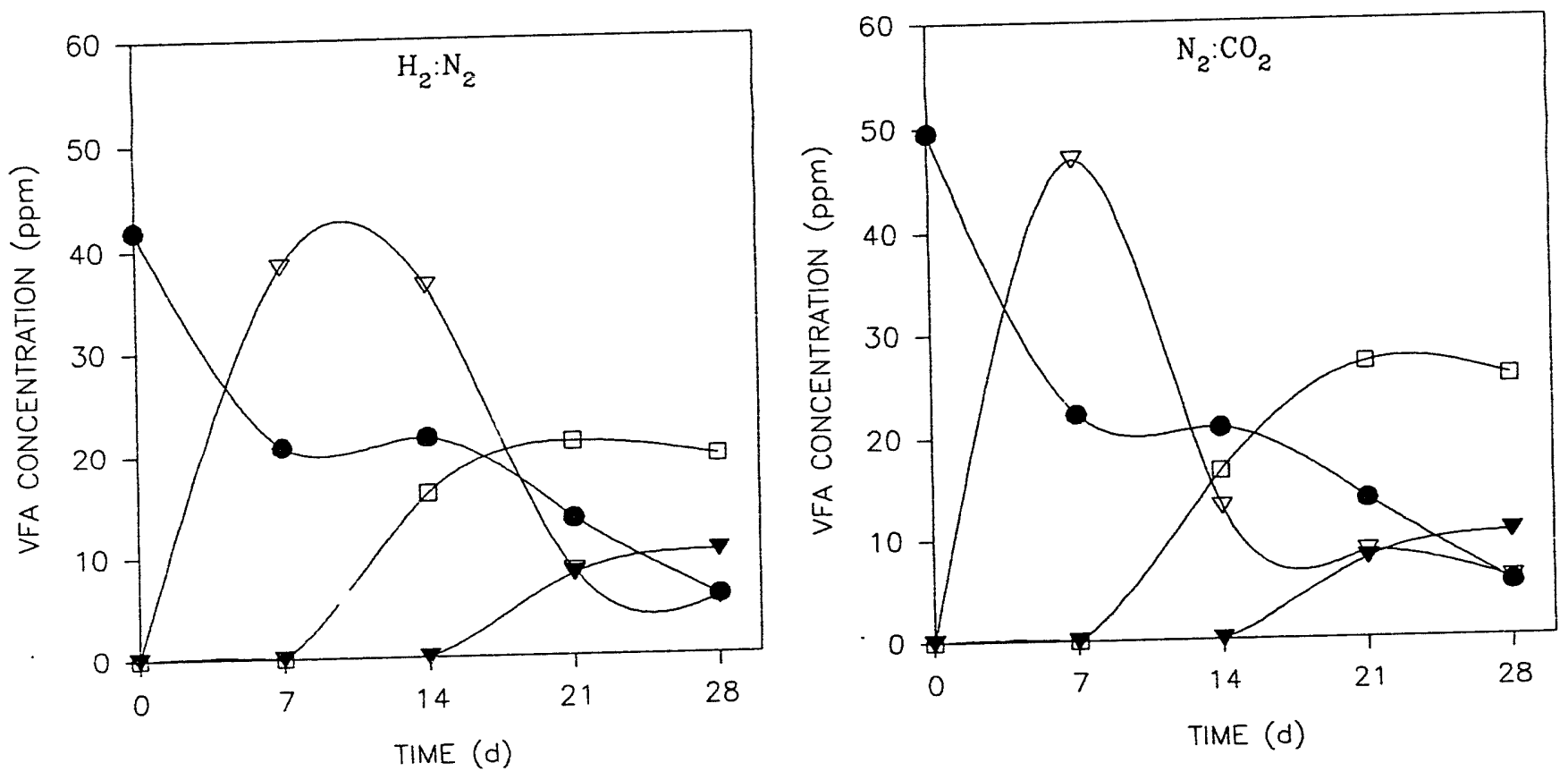

- Acetic $\nabla$ Isovaleric

Isocaproic $\square$ Heptanoic

Figure 2. Time Course of VFA Concentrations During Biomethanation of $1 \%$ Texas Lignite by the $10 \%$ Granulated Sludge Consortium 
$10 \% \mathrm{TxL}$
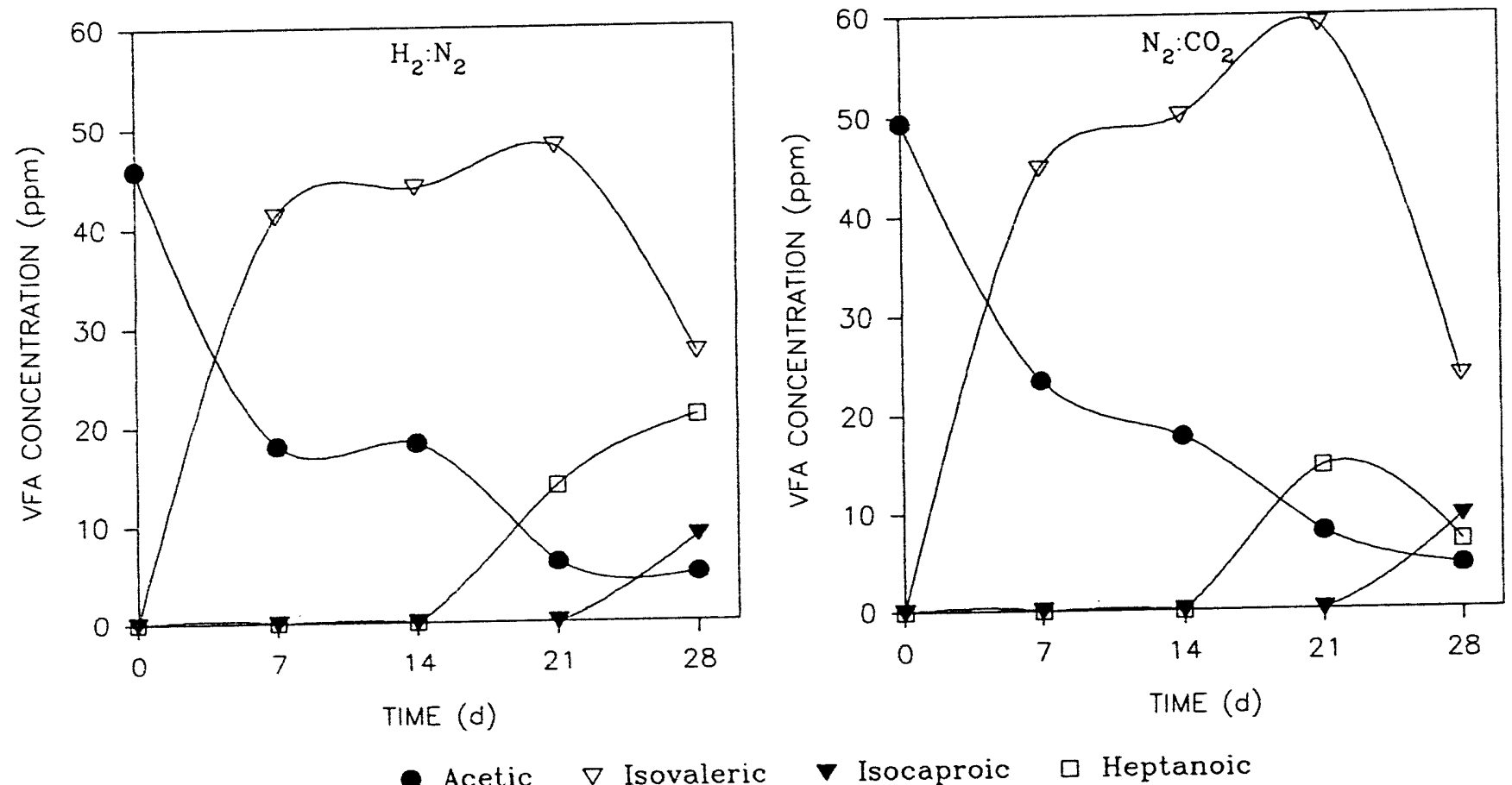

- Acetic $\nabla$ Isovaleric

Isocaproic

Figure 3. Time Course of VFA Concentrations During Biomethanation of $10 \%$ Texas Lignite by the $10 \%$ Granulated Sludge Consortium 


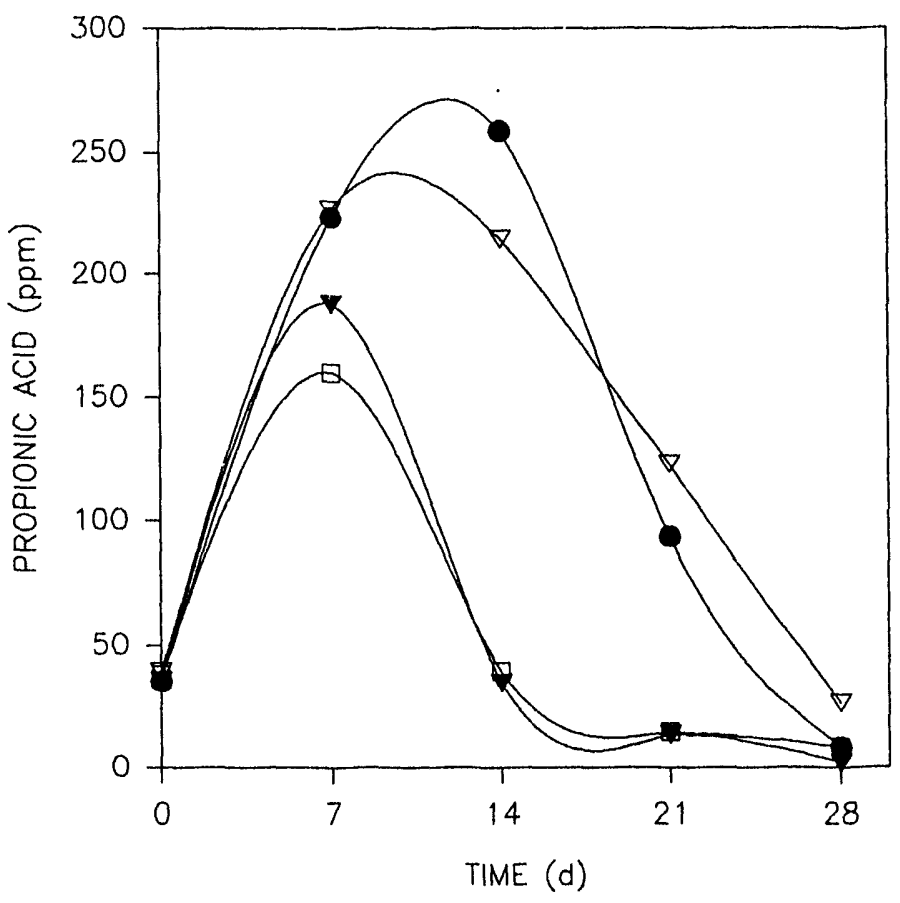

- $1 \% \mathrm{~T} \cdot \mathrm{L}\left(\mathrm{H}_{2}: \mathrm{N}_{2}\right) \quad \nabla 1 \% \operatorname{TxL}\left(\mathrm{N}_{2}: \mathrm{CO}_{2}\right)$

$\nabla 10 \% \operatorname{TxL}\left(\mathrm{H}_{2}: \mathrm{N}_{2}\right) \cdot \square \quad 10 \% \operatorname{TxL}\left(\mathrm{N}_{2}: \mathrm{CO}_{2}\right)$

Figure 4. Time Course of Propionic Acid Concentrations During Biomethanation of $1 \%$ and $10 \%$ Texas Lignite by the $10 \%$ Granulated sludge consortium 

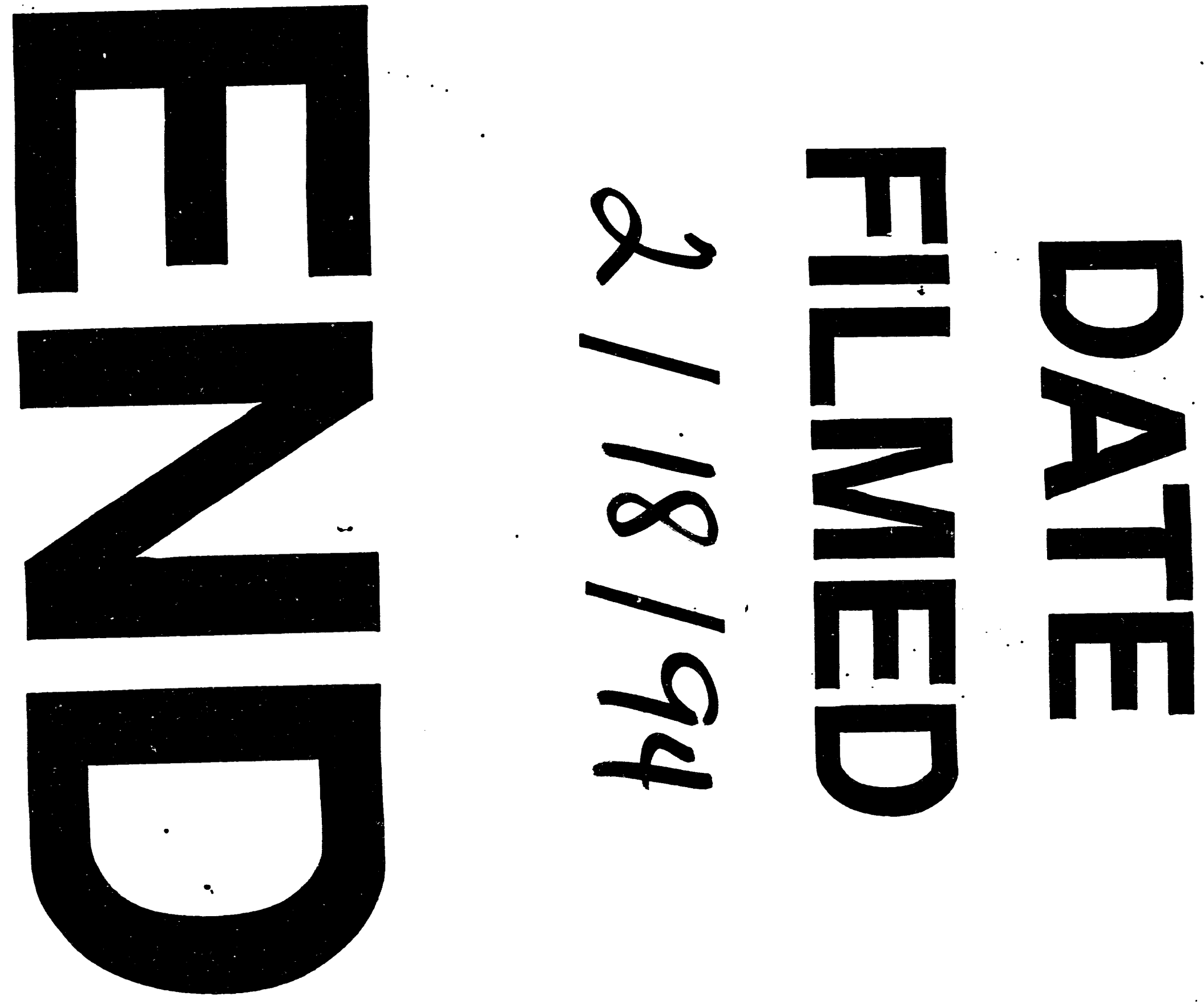
